\title{
Automatic Concept elassification of Text From Electronic Meetings
}

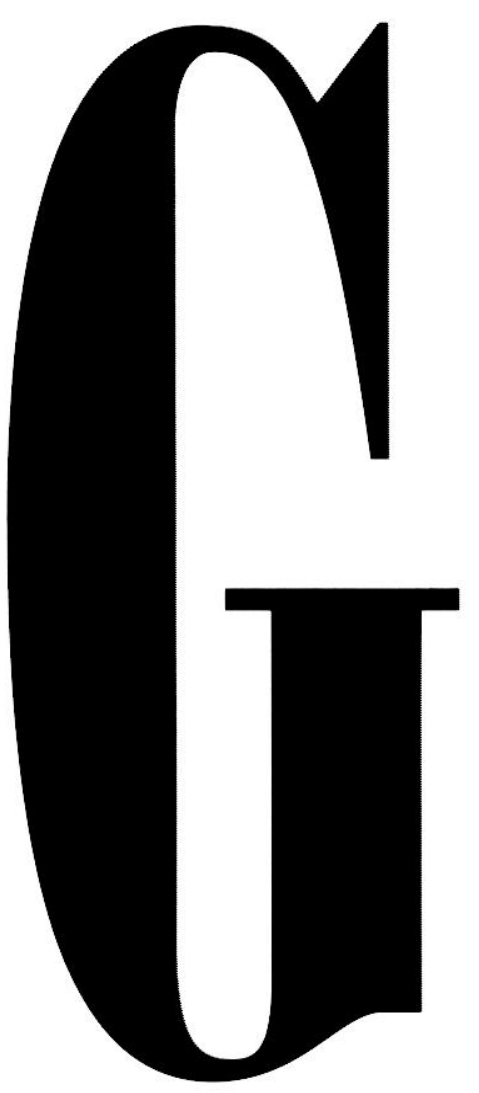

roupware, specialized computer aids that are designed for use by collaborative work groups [12], has produced measurable productivity gains for major corporations in recent years. Software for electronic meetings [18], in particular, can help reduce the time required for managers to complete complex projects by $90 \%$, according to a recent article in Fortune [13]. Electronic meeting software helps improve meeting quality by permitting anonymous comments over networked computers and by encouraging equal membership participation during a meeting.

A major advantage of the meeting software is its ability to let meeting participants brainstorm ideas in a parallel mode. Brainstormers can sit around a table and "talk" at the same time, using their keyboards. Often as many as several hundred comments can be generated by a group of 10-20 meeting participants during a typical one-hour electronic brainstorming (EBS) session. While meeting software has been shown to be extremely useful for idea generation, a divergent task, the process of identifying crucial ideas embedded in meeting comments and generating a consensus list of important topics (idea organization), a convergent task, is more difficult.

The overwhelming volume of brainstorming comments that have been produced using meeting software creates a burden for meeting participants during idea organization. When this process becomes a bottleneck, as is often the case, it counteracts the productivity gains and reduces the satisfaction of meeting participants.

In this research we adopted an artificial intelligence (AI) approach to designing an automatic concept classification tool for electronic brainstorming output. The role of AI techniques such as machine learning and neural networks computing in groupware development can be significant. Through extensive content analysis, concept space generation, and neural network-based concept classification, our system can generate a tentative list of the important ideas and topics represented in meeting comments. Participants then can examine the system's suggested list and the underlying comments. They can also revise or augment the list to produce their final consensus list. Allowing the system to act as an "intelligent" aide for idea organization can alleviate some of the burdens of convergent tasks.

\section{Concept Classification for Electronic Brainstorming Output: The Problem}

Groupware, defined as "computer-based systems that support groups of people engaged in a common task (or goal) and that provide an interface to a shared environment" [6], is designed to enhance human communication, collaboration, and coordination. Over the past decade, among the many applications that have been developed are message systems, multiuser editors, electronic meeting systems, computer conferencing, intelligent agents, and coordination systems. 
Electronic meeting systems (EMS) typically include several networked stations, large computer-controlled public displays, audio-video equipment, and electronic meeting software. Groups using such systems have been found to generate more unique alternatives for creative tasks than groups without such support, and the quality of decisions made on an intellective task is in general better for EMS groups than for non-EMS groups, although F.MS groups have been found to be less likely to reach complete consensus than non-EMS groups in controlled experiments. However, field studies with real groups have shown that EMS support assists the group in reaching consensus. (For a good overview, readers are referred to [9], [6], and [18]). While the EMS tools are useful in exploring ideas and generating alternatives, we need to improve upon the methods for consolidating ideas and reaching consensus.

The study described in this article was based on a specific electronic meeting system, the GroupSystems software and methodology developed at the University of Arizona [13, 18] and made commercially available through the University of Arizona spin-off company, Ventana Corporation. A pioneering example of meeting software technology, GroupSystems has been installed at more than 80 universities and a total of 400 organizational sites including business, government, and universities, where GroupSystems supports a variety of tasks. Many groups follow a common sequence of use, with meetings typically beginning with participants generating ideas. These ideas are then organized into a list of key issues, which the group can prioritize into a short list. The group will next generate ideas for action plans to address the important issues and then proceed to more idea organization and prioritization and so on.

Among the dozen or so tools in GroupSystems (see Figure 1), Electronic Brainstorming, Topic Commenter, and Group Outliner are considered Idea Generation tools; Idea Organizer, Issue Analyzer, and Group Writer are considered Idea Organization tools; Vote Selection, Al-
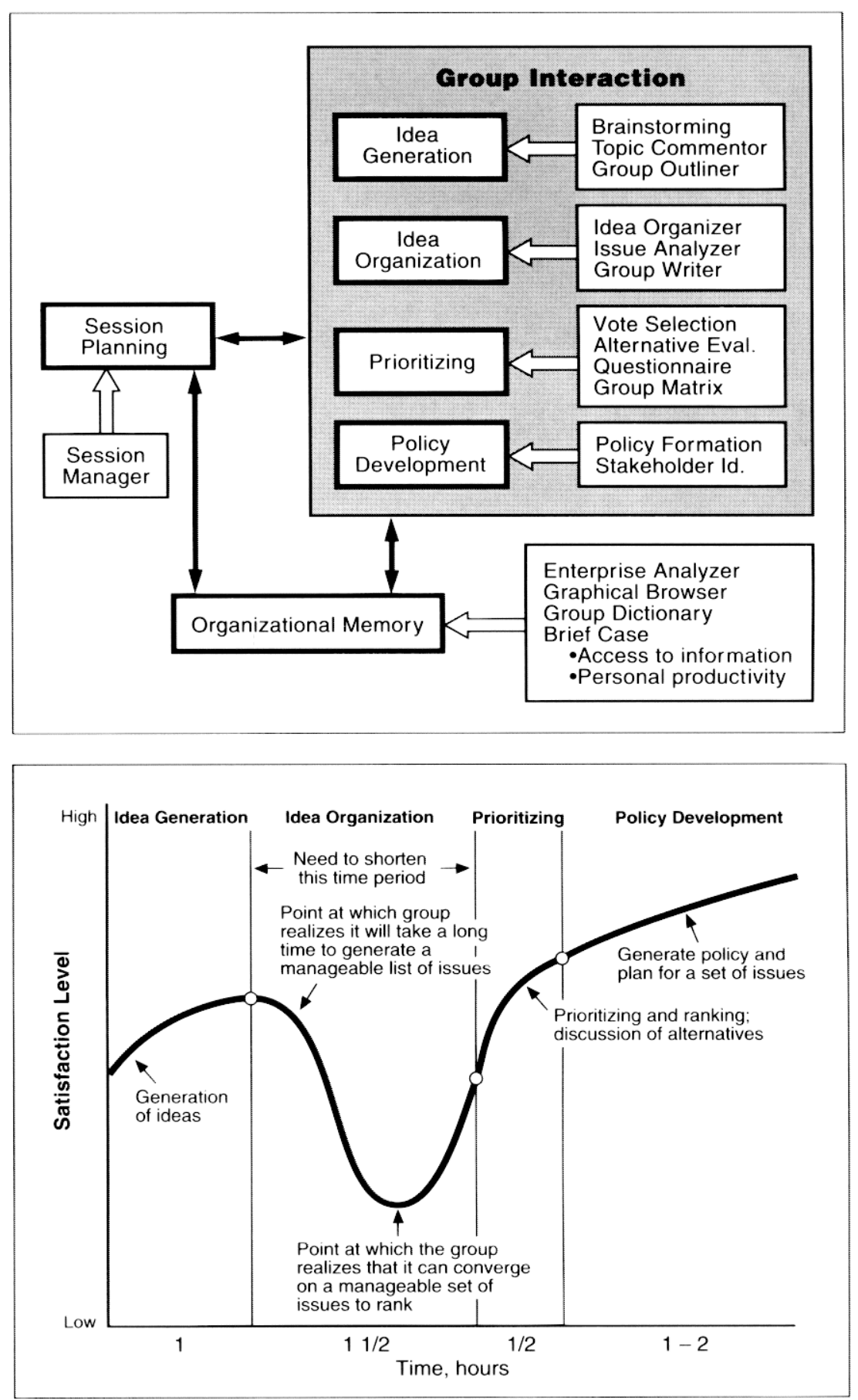

ternative Evaluation, Questionnaire, and Group Matrix are considered Prioritization tools; and Policy Formation and Stakeholder Identification are Policy Development tools.

A typical group of $10-20$ participants will generate anywhere from 500 to 1,000 lines of text in one hour during a brainstorming session. During this Idea Generation process, the group feels energized as it recognizes
Figure 1. Group Systems tools

Figure 2. Satisfaction level as a function of tool usage 
how great a contribution is being made to the question posed. The group members' overall satisfaction level increases, as shown in Figure 2. The next phase (Idea Organization) is to condense the list of comments into a manageable list of issues or topics. As group members perceive that finding all of the duplications and redundancies on the list is going to be very difficult and time consuming, the satisfaction level starts to fall. When the group senses that a manageable list of issues, often between 10 and 15 items, has been reached, then the satisfaction level starts to climb again. As the group settles on a set of issues upon which to vote, the satisfaction level continues to go up and the group proceeds to complete its task (Prioritizing and Policy Development in Figure 2).

EBS and Idea Organizer (IO), in particular, have been used most frequently and consistently in the first two phases. EBS allows group members to enter comments or ideas simultaneously and to share them anonymously. Idea Organizer allows participants to identify and consolidate ideas, typically by separately suggesting topics or ideas that merit further consideration by the group. During the consolidation of ideas, group members can browse the list of EBS comments and interact verbally with each other and the facilitator to condense the topic list to a manageable size by eliminating redundant, extraneous, or irrelevant topics. While the EBS process is often productive, use of the IO process to organize the EBS comments is complicated, for the following reasons.

- Information overload: successful use of the EBS tool, which generates a large number of ideas, has been found to result in an unexpected information overload problem. In a typical meeting of 10-20 participants, several hundred EBS comments can be generated in less than an hour, making it extremely difficult for participants to browse comments and consolidate ideas. The participants are often impressed with the number of ideas they have generated, but become overwhelmed with the task of orga- nizing the ideas into categories.

- Cognitive demand for convergent tasks: EBS comments need to be consolidated and organized by meeting participants within a short period of time. Usually each participant has to browse and understand the ideas generated in the EBS comments, judge the merits of these ideas, merge similar ideas, eliminate redundant or irrelevant ideas, consult other members' opinions, and so on in less than an hour. Because the EBS process encourages creative, diverse, and uncensored ideas, many EBS comments are raw or unpolished, and it may require special effort from meeting participants to synthesize them. Because the group concept organization process is sometimes frustrating and suboptimal, the satisfaction level and productivity of the meeting participants may go down significantly, as shown in Figure 2, and/or some unique EBS ideas may be lost during the cognitively demanding process.

Experiences in using GroupSystems has revealed that the parallelism and anonymity characteristics of the electronic meeting systems facilitate rapid development of ideas and make the tools appropriate for divergent tasks such as Idea Generation. However, for convergent tasks such as Idea Organization, the problems of equivocality during synthesis, consolidation, and consensus building often cannot be resolved by using the current "passive" groupware design. A more "pro-active" and "intelligent" groupware component may be needed to assist in the analysis of information and in enhancing consensus building.

\section{- Meeting memory management} and retrieval: GroupSystems incorporates some basic tools that enable meeting participants to access their previous online meeting transcripts (stored in text files or in databases). For example, Briefcase provides read-only access to any text file in the meeting memory, and Group Dictionary enables the group to develop and store formal definitions for use in meetings. Nevertheless, the meeting output management and retrieval capabilities of Group-

Systems, like those of most other meeting software, requires further enhancement.

In addition to a more convenient full-text searching capability, meeting software needs to be more powerful in assisting groups to construct a coherent and semantics-rich "meeting memory." Based on the human information-processing metaphor [17], meeting output should be indexed, stored, and organized as part of a larger organizational memory, ' helping managers and decision makers recognize opportunities and threats and draw inferences from past experiences and decisions which reside in meeting records. Meeting comments, decisions, plans, etc. should be stored in a finer granularity (i.e., each comment, decision, plan, and so on should be treated as a basic information unit) and made accessible in an online meeting environment. The amount of time managers spend in meetings, the levels and impacts of decisions made at meetings, and the often similar scenarios and situations faced by managers suffice to make relevant previous meeting comments, plans, and ideas significant factors in current decision making. A meeting memory component that can break the linearity of hard-copy meeting transcripts and allow meeting participants to search specific "relevant" ideas, topics, and comments should make electronic meeting systems more active and useful in creating a comprehensive, timely, and accurate organizational memory. This research sheds light on the development of such systems.

\section{An Algorithmic Approach to Concept Classification}

Text analysis and concept classification have long been challenges for information science and AI researchers $[7,16,21]$. In order to address the idea consolidation and organization

\footnotetext{
'Organizational theorists have defined organizational memory in terms of standard operating procedure, past events, promises, assumptions, behaviors, cause maps, architecture, strategic orientation, and memory retention facility [24]. The importance of organizational memory for intelligence development and decision making has been well recognized by behavioral scientists [11].
} 
problems discussed earlier, we adopted techniques that already had been developed in these areas. Before we present the specific techniques chosen, we first describe the unique characteristics and constraints of our application.

- Noisy input: although meeting software like GroupSystems allows meeting participants to enter and edit their comments using a simple editor, the constraints of meeting time and variations in participants' typing skills make EBS comments often quite "noisy." Incomplete or ungrammatical sentences are common. Typos often crop up in the comments. Lower and upper cases may be used interchangeably. Comments may vary in size, ranging from a few words to multiple paragraphs. In order to perform automatic concept classification, the system needs to be able to filter this noisy output and extract important ideas from the comments.

- Domain independent: the general-purpose, domain-independent role of meeting software also poses a special challenge for system designers. Electronic meeting software is designed to support any kind of meeting - to be applicable to any tasks, any meeting participants, and any institutions. The subject matters discussed in the meeting may vary widely, ranging from technical assessment of product design to an institution's long-term marketing plan. The diversity of vocabularies and jargons used in meetings may make infeasible the use of some domain-dependent, AI-based natural language parsing techniques such as semantic grammar (using domain-specific semantic categories in a grammatical structure) or $s e$ mantic constraint (imposing domain restrictions on the parameters of predicates).

- Real-time classification: meetings often follow preset agendas and are constrained by tight schedules. The EBS comments generated in one session need to be consolidated and organized in a following IO session. After a one-hour EBS session and a short break of 10-15 minutes, meeting participants are often ready to move on to the idea consolida- tion stage. Any active system component designed for EBS comment classification needs to perform analysis and classification within this time constraint. (We set a target processing time of 15 minutes for our prototype system.) After a short "coffee break," the system should be able to present its suggested list of the topics that had been addressed in the previous EBS session and allow meeting participants to make necessary changes or refinement. Time-consuming text analysis techniques are unsuitable for use in this application.

Based on these characteristics of electronic meetings and our experience with several useful AI and information retrieval-based algorithms, we selected techniques from the following three areas: automatic indexing, cluster analysis, and Hopfield net classification.

Automatic indexing has been used widely in information science for identifying subject descriptors of textual documents [19]. Cluster analysis [7], which is mainly based on statistical cooccurrence of descriptors in objects, has been used for automatic thesaurus (or concept space) generation of domain-specific databases [2]. And finally, resurgent neural network computing such as the Hopfield net algorithm [23] has been shown to be useful in performing memory association and classification [3].

In this research, we used automatic indexing to identify terms (single words and multiple words) from the EBS comments. Cluster analysis technique was then adopted to identify cooccurrence probabilities (representing the degrees of similarity) between any two terms. Finally, we used the Hopfield net algorithm to group similar terms, i.e., terms which represent similar ideas. Each group of terms then represented a unique topic. We review these techniques in the context of our research.

1. Automatic Indexing: the first task for EBS concept classification is to identify the content of each individual EBS comment. AI-based natural language processing techniques such as the Augmented Transition Network (ATN) parsing [25], case gram- mar [8], and semantic grammar [1] have been used by different researchers for creating unambiguous internal representation of English statements. However, ATN parsing has helped but not solved the general problem of text understanding, and it cannot represent the semantics of text (only syntactic categories are represented). A semantic analysis technique such as semantic grammar, which requires extensive knowledge about the semantic categories and relationships between objects in the application domain, is difficult to use in classifying generic meeting output.

An alternative method for content identification that is simple and domain independent is the automatic indexing method, often used in information science for indexing literature. Salton [19] presents a blueprint for performing automatic indexing, which typically includes dictionary look-up, stop-wording, word stemming, and term-phrase formation. Because of its computational efficiency and performance, a simple automatic indexing approach has been shown to be appropriate for content identification, so we adopted it for this research.

2. Cluster Analysis: while automatic indexing identifies subject descriptors in a document, the relative importance of each descriptor for representing the content of the document may vary. Salton's Vector Space Model associates with each descriptor a weight to represent its descriptive power. Among the many probabilistic techniques that have been developed by various information science researchers, techniques which typically incorporate term frequency and inverse document frequency have been found to be quite useful [19]. The basic rationales underlying these two measures are that: terms which appear more times in a document should be assigned higher weights (term frequency), and terms which appear in fewer documents in the whole database (the more specific terms) should have higher weights (inverse document frequency).

Based on cluster analysis ${ }^{2}$ [7], the Vector Space Model has been extended for automatic thesaurus generation (or automatic knowledge base gener- 
ation). The first stage in many cluster analyses is to covert the raw data (e.g., indexes and weights) into a matrix of interindividual similarity, dissimilarity or distance measures. The result of a cluster analysis will be a number of groups, clusters, types, or classes of individuals [7]. In automatic thesaurus generation [2, 4, 21], the most commonly used algorithms compute probabilities of indexes cooccurring in all documents of a database (sometimes referred to as the cooccurrence analysis). Just as a human inductive learning process generates concepts from a set of examples and benefits from the largest possible number of examples, a thesaurus created from a textual database becomes more knowledgeable as it becomes more subject specific and has more collections.

In [2] we developed an automatic thesaurus for Russian computing researchers from a textual database of 40,000 Russian computing documents and referred to the network that is generated from the cooccurrence analysis as a concept space, which represents the concepts embedded in the texts and their semantic relationships. For EBS comments, the subject matter discussed in a meeting, which is often very specific, i.e., problem specific, project specific, department specific, etc., and the large number of comments generated provide a sound basis for performing cluster analysis.

\section{Hopfield Net Classification:} when pairwise similarities are obtained between all term pairs, a hierarchical agglomerative cluster generation process is often adopted [19]. The cluster generation process aims to group (link) similar term pairs together. Several alternatives for linkingsimilar termsexist:single-linkclustering and complete-link clustering [19, 22].

While these information retrievalbased clustering methods have demonstrated their usefulness in clustering documents, a somewhat newer

${ }^{2}$ It was defined by Everitt as: "Given a number of objects or individuals, each of which is described by a set of numerical measures, devise a classification scheme for grouping the objects into a number of classes such that objects within classes are similar in some respect and unlike those from other classes." Other terminologies such as classification and taxonomy have also been used by statistical, AI, and IS researchers, in addition to clustering [16, 21]. approach based on the connectionist paradigm, or neural network computing has attracted a resurgence of interest [14]. There are several reasons for this, including the appearance of faster digital computers on which to simulate large networks, interest in building massively paralle computers, and, most importantly, the development of new neural network architectures and algorithms. Many neural network algorithms demonstrate excellent properties for solving classification problems

After a review of numerous networks $[14,15]$ and based on our experience and experimentation with several major networks [3], the Hopfield net [10], which was introduced as a neural network that can be used as a content-addressable memory, appeared to be a natural candidate for EBS ideas classification. Knowledge and information can be stored in single-layered, interconnected neurons (nodes) and weighted synapses (links) and can be retrieved based on the network's parallel relaxation and convergence methods. The Hopfield net has been used successfully in the past few years in such applications as image classification, character recognition, and robotics $[14,23]$, and we have also adopted it for concept-based information retrieval in [3].

The parallel relaxation and convergence properties of Hopfield net activation and its novel characteristics for memory association and classification led us to experiment with this newer approach for EBS comment classification.

\section{Automatic Concept Classification for EBS Output: The Solution}

An example of EBS comment analysis and classification based on actual electronic brainstorming output is also given for illustration. An evaluation of the performance of our prototype system was conducted, and the results will also be presented.

The EBS comments generated from an electronic meeting exhibit some unique characteristics which warrant discussion. The basic information unit in an EBS session is a textual comment entered by a meeting participant. It often consists of one or a couple of short paragraphs. A sample EBS question and associated EBS comments are shown in Figure 3.

It is not usual to see typos (e.g. "enginer" in comment 2.3), special abbreviations (e.g., "fab," "qa," and "PDS" in comment 2.3), incomplete sentences (e.g., "LACK OF STREAMLINED BACK END EXTENDING FROM SILICON TO PRODUCTION" in comment 1.10), or semigrammatical phases (e.g., "Accountability a serious problem" in comment 2.2). Upper case and loweı case are often used interchangeably by meeting participants, e.g., comment 1.10. The numeric identifier associated with each comment is as signed by the EBS program automatically based on the order in which comments are produced. Meeting participants can respond to other people's ideas by addressing these comment identifiers directly, e.g., comment 2.5 in Figure 3 responded to comment 2.3. Some comments are very general, e.g., comment 3.2 ("organization"), while others are very specific, e.g., comment 1.10 ("LACK OF A STREAMLINED BACK END EXTENDING FROM SILICON TO PRODUCTION ...").

Typically for a one-hour session with a dozen or so participants, the number of EBS comments generated is on the order of a few hundred. For example, 327 comments were generated by 18 meeting participants (managers and engineers of a manufacturing firm) in the 40-minute EBS session shown in Figure 3. After the EBS session these meeting participants spent another 50 minutes generating a list of important topics using IO.

\section{Automatic Indexing}

We decided to treat each meeting comment as a document, the basic information unit for our automatic indexing and cluster analysis procedures. As evident in the comments shown in Figure 3, the often noisy and ungrammatical nature of the EBS comments made linguistic-based natural language processing techniques less appealing. The EBS comments, however, revealed that a majority of the ideas proposed were 
expressed in simple terms or phrases. An automatic indexing procedure which generates subject descriptors [19] was selected for this application. We adopted the following steps for automatic indexing:

(1) Word identification: our system first identified words in a comment, ignoring punctuation and case. The comment number, paragraph number, sentence number, and word number associated with each word were also stored.

(2) Stop-wording: we developed a "stop word" list which included about 1,000 common function (nonsemantic bearing) words, such as on, in, at, this, there, etc. and "pure" verbs (words which are verbs only), e.g., calculate, articulate, teach, listen, etc. This list was used to delete highfrequency words that are too general to be useful in representing document content.

(3) Stemming: we adopted a stemming algorithm to identify the word stem for each remaining word-a reverse of the suffixing procedure. The stemming component consisted of two parts. First it included a 28,000-word (root words) dictionary with flags indicating legal suffixed forms. The total number of words our system recognized was about 80,000 . We also included about 30 rules to interpret the flags for suffixes. The 22 suffixes that could be stemmed by this algorithm included: ive, ion, tion, en, ions, ications, ens, th, ieth, ly, ing, ings, ed, est, er, ers, s, es, ies, ness, iness, and 's. A few sample rules are shown in Figure 4.

(4) Term-phrase formation: we then used adjacent words to form phrases. After examining the meeting output, we decided to form phrases which contained up to three words-most subject descriptors are less than four words. Our system generated 1-word, 2-word, and 3-word phrases from adjacent words, e.g., "information," "retrieval," "system," “information retrieval," "retrieval system," and "information retrieval system" from the three adjacent words "information retrieval system" in the EBS comment. We will refer to these phrases as "terms" in the remainder of this article.

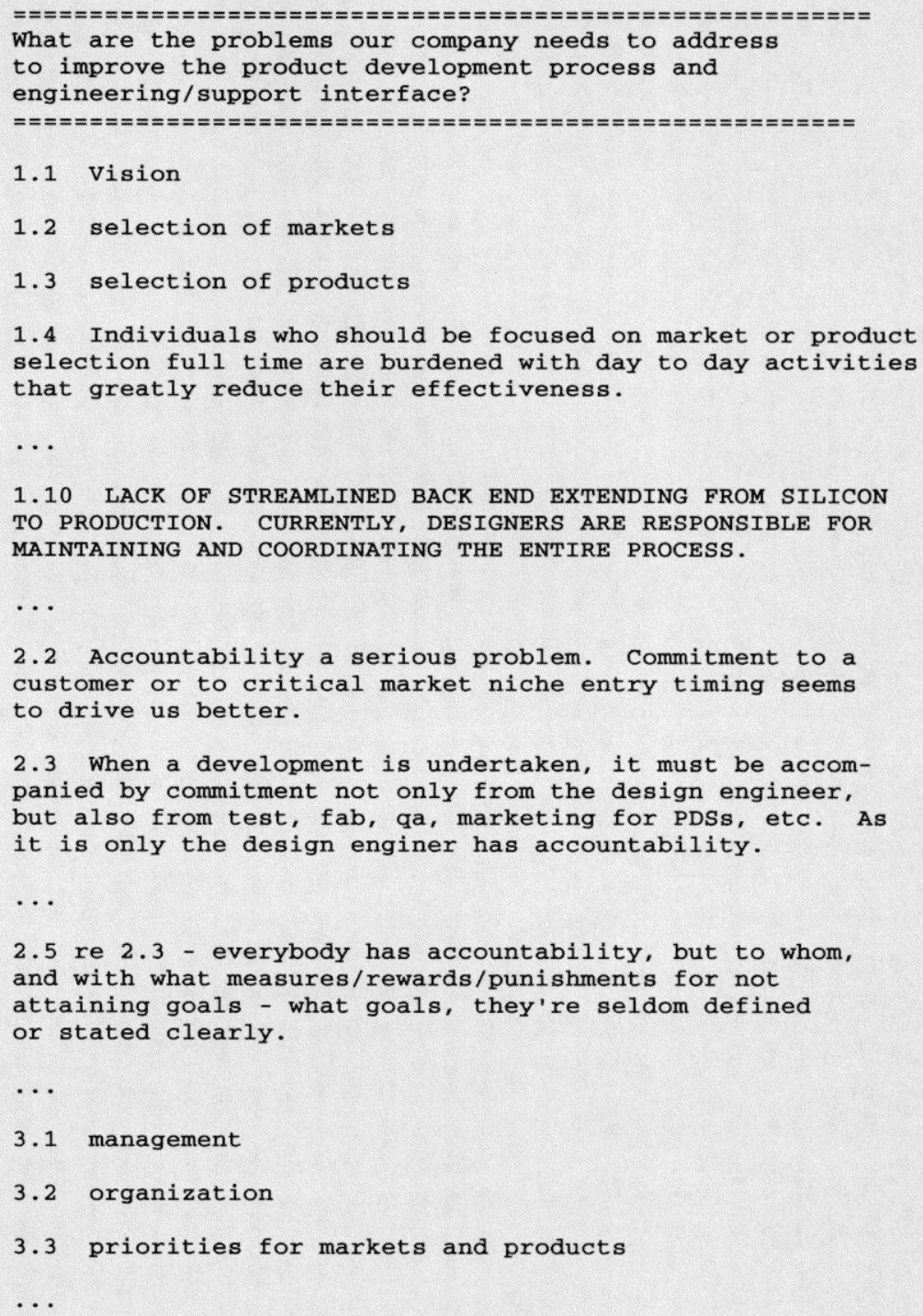

1.10 LACK OF STREAMLINED BACK END EXTENDING FROM SILICON TO PRODUCTION. CURRENTLY, DESIGNERS ARE RESPONSIBLE FOR MAINTAINING AND COORDINATING THE ENTIRE PROCESS.

$\cdots$

2.2 Accountability a serious problem. Commitment to a customer or to critical market niche entry timing seems to drive us better.

2.3 When a development is undertaken, it must be accompanied by commitment not only from the design engineer, but also from test, fab, qa, marketing for PDSs, etc. As it is only the design enginer has accountability.

$\cdots$

2.5 re 2.3 - everybody has accountability, but to whom, and with what measures/rewards/punishments for not attaining goals - what goals, they're seldom defined or stated clearly.

$\cdots$

3.1 management

3.2 organization

3.3 priorities for markets and products

$\cdots$

\section{Figure 3. Sample EBS comments}

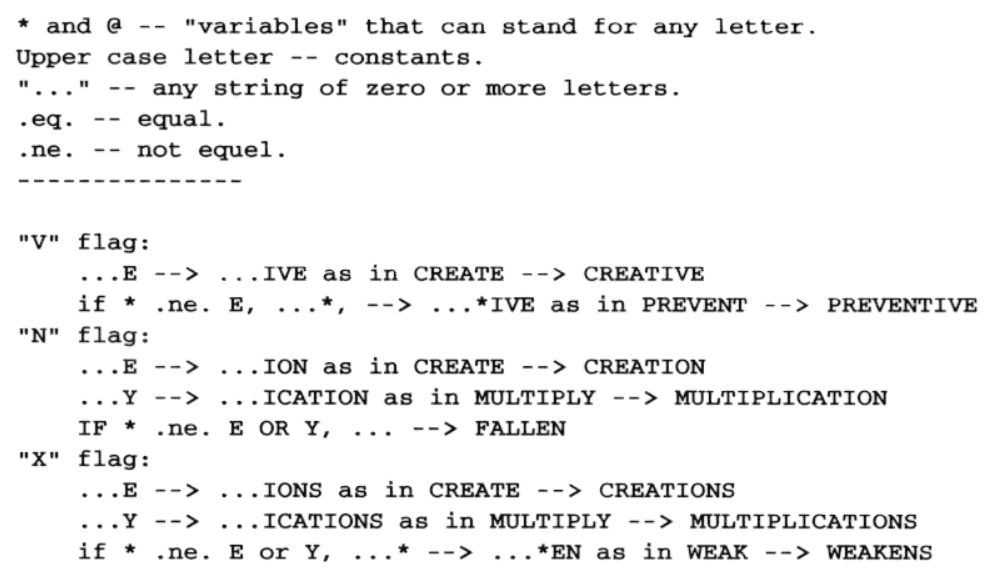

Figure 4. Examples of stemming/suffixing rules 
11111 VISION

21111 SELECTION

21121 MARKET

31111 SELECTION

31121 PRODUCT

41111 INDIVIDUAL

41121 MARKET

41131 PRODUCT

41132 PRODUCT SELECTION

41133 PRODUCT SELECTION FULL

41141 SELECTION

41141 SELECTION FULL

41141 SELECTION FULL TIME

41151 FULL

41152 FULL TIME

$$
\text { : }
$$

PRODUCT $\mathrm{df}=101$

DESIGN $d f=59$

MARKET $d f=36$

TIME $\mathrm{df}=34$

DEVELOPMENT $\mathrm{df}=34$

SUPPORT $\mathrm{df}=28$

ENGINEER $\mathrm{df}=28$

SCHEDULE $\mathrm{df}=24$

PRODUCT DEVELOPMENT $\mathrm{df}=22$

REALISTIC $\mathrm{df}=5$

REQUIREMENT $d f=5$

DEFINE $d f=5$

SIGN df $=5$

PRODUCT : DESIGN: 0.1869

PRODUCT : DEVELOPMENT: 0.1107

DESIGN : PRODUCT: 0.3460

MARKET : PRODUCT: 0.3373

MARKET : DESIGN: 0.1887

TIME : DESIGN: 0.1242

TIME : PRODUCT: 0.1179

TIME : SCHEDULE: 0.1023

Figure 5. Automatic indexing output

Figure 6. Terms ranked according to document frequency

Figure 7. Co-occurrence tables
The EBS output, after automatic indexing, consisted of a list of terms (indexes). Part of the automatic indexing output produced for the manufacturing session discussed earlier is listed in Figure 5. The number of unique terms generated from the 327 manufacturing comments was 2,384. All terms are represented in upper case. In each row, the first column indicates a unique identification number for a comment. Columns 2, 3 , and 4 represent the paragraph number, sentence number, and word number of the term, respectively. Column 5 represents the word countnumber of words in a term. For example, "PRODUCT SELECTION" which consisted of 2 words, appeared in Comment 4, Paragraph 1, Sentence 1 , Word 3.

\section{Cluster Analysis}

After indexes had been assigned to each comment, we proceeded to identify the cooccurrence pattern of indexes which appeared in all comments. A similarity measure similar to the popular Cosine function [19] was adopted. This function, which we referred to as the Cluster Function, had shown better performance than the Cosine function for creating a domain-specific automatic thesaurus [2]. The basic difference between the two functions is that the Cosine Function produces symmetric links, but the Cluster Function produces asymmetric links. Based on the Cluster Function, our system generated a network called concept space to represent the weighted relationships between indexes (concepts) in the documents.

1. Term frequency and document frequency computation: we first computed the term frequency, $t f_{i l}$, which represents the number of occurrences of term $j$ in document $i$ and the document frequency, $d f_{j}$, which represents the number of document. in a collection of $n$ documents in which term $j$ occurs.

2. Determining threshold through information loss analysis: we then performed an information loss analysis in order to determine the threshold for removing uncommon terms (e.g., typos and unique abbreviations) and for generating a set of consensus terms for further analysis. Only indexes that passed the threshold were considered in the following concept classification process. An EBS comment was considered "lost" if all its indexes appeared less often than a specified document frequency threshold. These "lost" comments, however, can still be retrieved through index search or browsing.

Our algorithm incrementally increased its document frequency threshold, i.e., l occurrence, 2 occurrences, 3 occurrences, and so on until it produced an information loss level closest to the desired level. Based on our experimentation, the threshold produced by the information loss analysis was extremely useful for trimming the number of indexed terms, and helping to reduce the computation required for the polynomial $\left(O\left(n^{2}\right)\right)$ cluster analysis procedure. In our testing, we found that when we set the information loss level at $10 \%$, the resulting occurrence threshold was about 3-6 (for differ ent sessions), which caused the num ber of index terms to drop from a few thousand to a couple of hundred This reduction of the order of magnitude in the number of indexes was necessary to enable our system to focus on the consensus terms and to produce real-time classification.

As shown in Table 1 for the sample manufacturing session, after deter mining the threshold of 4 - the infor mation loss closest to $10 \%(89.91 \%$ of documents indexed) - the number of remaining unique index terms dropped from 2,384 to 111 . As will be discussed later the CPU time required for cooccurrence analysis of a few hundred terms was about two minutes. Without a proper threshold, the system might produce too many unique and sometimes noisy terms and also will not be able to finish its analysis within the real-time constraint. For example, typos or obscure terms such as "enginer," "qa," and "PRODUCT SELECTION FULL," which were produced erroneously from the prior automatic indexing procedure, did not pass the threshold and thus were not included for cooccurrence analysis.

Another interesting observation based on the information loss analysis 


\section{was that a small set of terms was used} overwhelmingly throughout the comments. For example, as shown in Table 1, the top 12 terms (the last row, 19 occurrences) appeared in $71.25 \%$ of the comments. This showed the frequency of use of consensus terms by meeting participants to express their ideas.

After applying the threshold, the remaining terms were ranked according to their decreasing order of document frequency. As shown in Figure 6 (from the same manufacturing session), terms which were used more often in the complete EBS output (e.g., "PRODUCT," "DESIGN," "MARKET," etc.) appeared to capture more consensus concepts in the meeting comments than terms that were used infrequently. (e.g., "SIGN," "DEFINE," etc.). But, on the other hand, the most frequently occurring terms may be too general to convey any specific and unique ideas represented in the EBS comments. Maintaining a balance in revealing the consensus concepts (general terms) and the unique ideas (specific terms) in the EBS comments was the ultimate challenge for our system development. A more detailed discussion will be presented in the evaluation section.

3. Combining weights: we then computed the combined weight of term $j$ in document $i, d_{i j}$, based on the product of term frequency and document frequency as follows:

$$
d_{i j}=t f_{i j} \times \log d f_{j}
$$

Notice that this computation is based on document frequency instead of the more conventional inverse document frequency $\left(\log n / d f_{j}\right)$ used in solving large-scale automatic indexing problems [19]. This change was made because of the need to identify the consensus topics in the EBS comments. We adopted document frequency in order to increase the weights associated with the more frequently used terms. In the conventional automatic indexing environment, however, the practice is to assign higher weights to more specific or unique indexes through inverse document frequency.

4. Concept space generation: based on the asymmetric Cluster Function shown below, we generated a net- work-like concept space or terms and

their weighted relationships.

$$
\begin{aligned}
& \text { ClusterWeight }\left(T_{j}, T_{k}\right)=\frac{\sum_{i=1}^{n} d_{i j k}}{\sum_{i=1}^{n} d_{i j}} \\
& \text { ClusterWeight }\left(T_{k}, T_{j}\right)=\frac{\sum_{i=1}^{n} d_{i j k}}{\sum_{i=1}^{n} d_{i k}}
\end{aligned}
$$

These two equations compute the similarity weights from term $T_{j}$ to term $T_{k}$ (the first equation) and from term $T_{k}$ to term $T_{j}$ (the second equation), where $d_{i j}$ represents the combined weight of descriptor $T_{j}$ in document $i, d_{i k}$ represents the combined weight of descriptor $T_{k}$ in document $i$, and $d_{i j k}$ represents the combined weight of both descriptors $T_{j}$ and $T_{k}$ in document $i . d_{i j k}$ is computed by:

$$
d_{i j k}=t f_{i j k} \times \log d f_{j k}
$$

where $t f_{i j k}$ represents the number of occurrences of both term $j$ and term $k$ in document $i$, and $d f_{j k}$ represents the number of documents in a collection of $n$ documents in which both term $j$ and term $k$ occur.

In order to obtain a reasonable number of cooccurred terms for each term, we adopted an empirically determined weight threshold of 0.1 . This threshold ensured that only the most relevant terms were represented in our final concept space. Figure 7 shows some partial cooccurrence tables generated by our system for the same manufacturing session. Notice that the weights between terms are asymmetric, e.g., the weight from "PRODUCT" to "DESIGN" was 0.1869 , but the weight from "DESIGN" to "PRODUCT" was 0.3460 .

\section{Hopfield Net Classification}

The final output from this process was a network of descriptors and their weighted relationships, akin to a neural network of nodes and weighted links. Our system adopted a variant of the Hopfield network activation procedure to identify clusters of relevant descriptors in the concept space through their weighted links. treated as a neuron, and the asymmetric weight between any two terms was taken as the unidirectional, weighted connection between neurons. Using each remaining term after information loss analysis as the individual input pattern, the Hopfield algorithm activated its neighbors, combined weights from all associated neighbors, and repeated this process until the output pattern converged. The resulting output revealed all other concepts that were semantically relevant to the input term. Repeating this process for all the terms according to their decreasing occurrence frequencies, we were able to identify the underlying, related concepts in the EBS comments. A sketch of the Hopfield net concept classification procedure follows:

1. Assigning connection weights: the concept space generated earlier represents the initial status of the Hopfield net. $t_{i j}$ represents the synaptic weight from node $i$ to node $j$.

2. Initialization with unknown input pattern:

$$
\mu_{i}(0)=x_{i}, 0 \leq i \leq n-1
$$

$\mu_{i}(t)$ is the output of node $i$ at time $t$, and $x_{i}$, which has a value between 0 and 1 , indicates the input pattern for node $i$. At time 9, the starting input node is assigned 1. As discussed earlier, each term is used individually as an input node for activation, i.e., at time 0 only one term receives the value 1 and all other terms receive 0 , and we repeat this initialization and the following activation process $n$ times.

\section{Activation and Iteration:}

$$
\begin{aligned}
\mu_{j}(t+1)=f_{s}\left[\sum_{i=0}^{n-1} t_{i j} \mu_{i}(t)\right] & \\
& 0 \leq j \leq n-1
\end{aligned}
$$

where $f$, is the continuous SIGMOID transformation function $[5,14]$ as shown below,

$$
f_{s}\left(n e t_{j}\right)=\frac{1}{1+\exp \left[\frac{-\left(n e t_{j}-\theta_{j}\right)}{\theta_{0}}\right]}
$$

where $n e t_{j}=\sum_{i=0}^{n-1} t_{i j} \mu_{i}(t), \theta_{j}$ serves as a threshold or bias, and $\theta_{0}$ is used to modify the shape of the SIGMOID function. This formula shows the par- 
neuron 0 (PRODUCT): 01411

neuron 1 (DESIGN): 01411

neuron 2 (SALE): 014

neuron 3 (MARKET): 014

neuron 4 (DEVELOPMENT): 01411

neuron 5 (TEAM): 01411

neuron 6 (ENGINEER): 014678112325

neuron 7 (SUPPORT): 014678112325

neuron 8 (PRODUCT ENGINEER): 014678112325

neuron 9 (SCHEDULE): 01411

neuron 10 (PROJECT): 01411

neuron 11 (PRODUCT DEVELOPMENT): 01411

neuron 12 (CUSTOMER):

neuron 13 (TESTING): 01411

neuron 14 (PROCESS): 014678112325

neuron 99 (PRODUCTION): 014

neuron 102 (STANDARD): 014

neuron 105 (RESPONSIBILITY): 0124567810112325374663108

neuron 108 (REQUIREMENT): 01411

neuron 109 (DEFINE): 01411

EBS question: "What are the problems our company needs to address to improve the product development process and engineering/support interface?"

\section{Topics classified}

** DESIGN/PRODUCT DEVELOPMENT

** SALE/PRODUCT ENGINEER/SUPPORT GROUP

** TEAM/PRODUCT ENGINEER/SUPPORT GROUP

** MARKET/PRODUCT DEFINITION/PLANNING/REQUIREMENT

** PROJECT

$\star \star$ CUSTOMER

** TESTING

** PROCESS

** SYSTEM

** PEOPLE

** MANAGEMENT

** SCHEDULE/CYCLE TIME/DEVELOPMENT CYCLE/CONTROL

** TEAM

** CHANGE

** GOAL

Figure 8. Hopfield net classification output

Figure 9. System-generated topics for the EBS comments

allel relaxation property of the Hopfield net.

4. Convergence: this process is repeated until there is no change between two iterations in terms of output, which is accomplished by checking empirically determined parameters were selected to control the degree of expansion of the parallel activation process such that only strongly relevant (associated) neurons (terms) eventually will be turned on. This tuning effort was as critical to our application as in other Hopfield net applications [14, 15].

Figure 8 shows a portion of the Hopfield net classification output for the same manufacturing case. We used each individual term as a starting input pattern (111 terms) and performed 111 rounds of Hopfield net spreading activation. These terms were activated according to their decreasing occurrence order, e.g., neuron 0 represents "PRODUCT," neuron 1 represents "DESIGN," neuron 3 represents "MARKET," and so on. In the list, each row shows the final convergent group of terms for each starting term. For example, neuron o, "PRODUCT," converged to four underlying neurons (terms), "PRODUCT," "DESIGN," “DEVELOPMENT," and "PRODUCT DEVELOPMENT" (neurons 0, 1, 4, 11 , respectively). Some neurons converged to more terms, e.g., neuron 6 converged to neurons $6,7,8,23$, and 25 ("ENGINEER," “SUPPORT," "PRODUCT ENGINEER,' "GROUP," and "SUPPORT (GROUP") in addition to neurons 0, 1,4 , and 11 .

Some neurons converged, but with no specific associated terms, e.g., neuron 12. Other neurons which were not listed never converged after a preset level of 100 iterations, e.g., neuron 100, 101, 103, 104, 106, 107, 110 ("SUCCESS," "PROPOSAL," "AUTHORITY," "RESOURCE," "REALISTIC," and "SIGN," respectively). Terms at the bottom of the list more frequently did not converge. These terms did not appear to relate to other consensus terms in the EBS output and thus never converged.

Interestingly, the two most frequently occurring groups of terms for this session, namely, neurons $0,1,4$, 11 which represent "DESIGN" and "PRODUCT DEVELOPMENT" and neurons $6,7,8,23,25$ which represent "PRODUCT ENGINEER" AND "SUPPORT GROUP," revealed the topics raised in the original meeting 
question: "What are the problems our company needs to address to improve the product development process and engineering/support interface?" Most consensus terms in the EBS comments appeared to evolve around these two crucial topics in the question.

After this complete activation process, terms which appeared together were grouped as a topic, e.g., terms 6 , $7,8,23,25$ were grouped and considered as one topic; terms 2, 5, 10, 37, 46, 63, 108 were grouped (within concept group: $6,7,8,23,25)$, and so on. Terms which converged to a specific group were considered a subconcept within the group. So "DESIGN/ PRODUCT DEVELOPMENT" was considered the top-most concept for this meeting output (all terms converged to these concepts), while other terms converged to some other more specific concept groups. In the final report we listed all convergent groups and supplemented the list with other frequently occurring terms to make up a list of 15 topics. The reason for choosing 15 topics was based on a heuristic suggested by meeting facilitators. The textual representation of the topics identified by our system for the manufacturing session is shown in Figure 9.

Our prototype system was developed in $\mathrm{C}$ and ran on a DECStation 5000/120 (25-MIPS machine). The EBS comments were extracted directly from GroupSystems as an ASCII file, and the system's classification output was represented in the textual format shown in Figure 9. For a typical EBS output of several hundred comments, the complete process of automatic indexing, concept space generation, and Hopfield net classification lasted about 7 minutes, well within our target time range.

\section{System Evaluation: An EBS Comment Classification Experiment}

In order to determine the performance and usefulness of our approach and to pinpoint directions for future research, we conducted an EBS comment classification experiment which compared the system's suggested list of topics with those generated by professional meeting facilitators. Four facilitators were cho- sen for their experience and expertise in guiding groups through the Idea Organization process. It was felt that their experience would have prepared them to develop some criteria as to what would make a good list.

The experiment consisted of two stages: a categorization stage and a list evaluation stage. In the first stage, each facilitator was presented with a complete set of brainstorming comments that had been generated by an actual group. Each facilitator was asked to create a list of topics that pertained to those comments. In the second stage, each facilitator was asked to critique five lists: three were generated by the other facilitators; one was generated by the actual group; and one was generated using our system. We did not

\begin{tabular}{|c|c|c|}
\hline $\begin{array}{l}\text { Term } \\
\text { threshold }\end{array}$ & $\begin{array}{c}\text { No. of unique } \\
\text { terms left }\end{array}$ & $\begin{array}{l}\% \text { of comments } \\
\text { indexed }\end{array}$ \\
\hline 0 & 2,384 & $100.00 \%$ \\
\hline 1 & 1,335 & $97.25 \%$ \\
\hline 2 & 434 & $95.41 \%$ \\
\hline 3 & 168 & $92.05 \%$ \\
\hline 4 & 111 & $89.91 \%$ \\
\hline 5 & 89 & $88.99 \%$ \\
\hline 6 & 60 & $86.54 \%$ \\
\hline 7 & 50 & $85.63 \%$ \\
\hline 8 & 38 & $83.18 \%$ \\
\hline 9 & 37 & $83.18 \%$ \\
\hline 10 & 32 & $81.04 \%$ \\
\hline 11 & 28 & $79.82 \%$ \\
\hline 12 & 25 & $79.82 \%$ \\
\hline 13 & 24 & $79.82 \%$ \\
\hline 14 & 21 & $79.20 \%$ \\
\hline 15 & 19 & $77.98 \%$ \\
\hline 16 & 16 & $74.92 \%$ \\
\hline 17 & 15 & $74.31 \%$ \\
\hline 18 & 15 & $74.31 \%$ \\
\hline 19 & 12 & $71.25 \%$ \\
\hline
\end{tabular}

allow facilitators to access their own lists during the list evaluation stage. There was approximately one week's lag time between the two stages for each facilitator.

We used two EBS sessions in our experiment: a manufacturing firm's session (the same sample shown throughout this article) and a session of business school educators. The four facilitators went through the first stage of the experiment (categorization) with both sets of data. Each facilitator spent about an hour in generating each list. Because of the difficulty of evaluating these lists, the facilitators went through the second stage of the experiment (list evaluation) with only the manufacturing firm's data.

\section{Table 1. Information Loss Analysis for the Manufacturing Session}


Table 2. Manufacturing Session Lists

\begin{tabular}{|c|c|}
\hline Subject 1: 50 mins. & Subject 2: 68 mins. \\
\hline 1. establish vision/goals/objectives & 1.focus/product selection/marketing \\
\hline 2. market (selection, forecasts) & 2. role of design/application engineer \\
\hline 3. selection of products & 3. scheduling/accountability \\
\hline 4. accountability/reward systems & 4. management structure \\
\hline 5. management/leadership & 5. resource allocation \\
\hline 6. communication/feedback/coordination & 6. customer input/involvement \\
\hline 7. process documentation/standards/project history & 7. reusable solutions \\
\hline 8. personnel roles/responsibilities & 8. standardized procedures/methodology/cost accounting \\
\hline 9. manufacturability & 9. design/engineer for manufacturability \\
\hline 10. resource allocation & 10. incentives for designers \\
\hline 11. scheduling/tracking (monitoring) & 11. role of support groups \\
\hline 12. lack of team orientation & 12. estimates/proposals/planning for product development \\
\hline \multirow[t]{2}{*}{ 13. process delays/serial nature/critical paths } & 13. project teams/effective follow through/completion \\
\hline & 14. quality of design/product \\
\hline Subject 3: 168 mins. & Subject 4: 60 mins. \\
\hline 1. organizational issues & 1. too many levels (or inappropriate levels) of management \\
\hline 2. marketing & 2. development personnel are saddled with line responsibilities \\
\hline 3. process issues & $\begin{array}{l}\text { 3. product definition/selection process requires a new more } \\
\text { rational approach }\end{array}$ \\
\hline 4. personnel issues & 4. too little standardization/basis across engineering processes \\
\hline 5. product issues & 5. military division requires evaluation \\
\hline 6. management & $\begin{array}{l}\text { 6. poor top management communication-perception of little } \\
\text { management focus and commitment }\end{array}$ \\
\hline \multirow[t]{2}{*}{ 7. technology (support) } & 7. insufficient product-engineering support \\
\hline & 8. lack of timely process development \\
\hline
\end{tabular}

Table 2 contains six lists of categorized topics pertaining to the manufacturing session. Four of these lists of topics were created by the four facilitators, respectively, i.e., Subjects 1, 2, 3 , and 4 . The session list contains the list of topics that the actual group created during its electronic meeting. The system list contains the topics generated by our Hopfield net classification scheme. The facilitators' lists for the education case are listed in the Appendix along with the data generated by the system.
During the list evaluation stage, the facilitator-subjects were asked to first rank the five lists. They were told that the lists came from other facilitators who had gone through the process. They were not told that one of the lists was produced by our system. Following the ranking, we asked the subjects to go through each list individually and evaluate all of them carefully. They were told that they could add topics that they felt were missing from a list or delete topics that they felt were inappropriate. If rewording or change of a topic was deemed necessary by the subjects, it would be treated as a deletion followed by an addition. For each list they evaluated, the subjects were asked to make necessary changes until they obtained a satisfactory list of topics.

\section{Experimental Results and Analysis} Table 3 shows the results of this list evaluation for the manufacturing session. The six lists that were analyzed are labeled across the top. The rank 
assigned to each list is given as the first row for each subject.

The Target number of items is the total number of items that was on the list after a subject completed additions, deletions, or merges. Thus, numbers in the target columns represent the total number of relevant concepts that the subject felt should be on each list. For example, Subject 2 felt that Subject 1's list should contain 15 items, and Subject 3 felt that the Group's session list should contain 19 items. Variations in terms used and the granularity of ideas represented in the lists resulted in subjects suggesting different numbers of target terms for each list. The Identified rows give the number of items that the originator of the list generated. The numbers on the Relevant row represent an intersection of the Target and Identified rows. The Relevant row indicates the number of items on the Identified list that are also on the Target list.

With the facilitator-suggested measures of Target, Identified, and Relevant concepts, we were able to determine the Concept Recall and Concept Precision of the various lists. Concept Recall is computed by dividing the number of Relevant items by the number of Target items and represents the percentage of relevant meeting ideas that were properly captured in the suggested list. Concept Precision is computed by dividing the number of Relevant items by the number Identified and represents the percentage of the concepts in the lists that are deemed relevant to the actual meeting topics. Values of these two measures are between 0 and 1 , and high Precision and Recall are desirable.
Table 3 indicates a clear distinction between the lists of Subjects 1 and 2 and the other lists. Not only did Subjects 1 and 2 rank each other's list as the best, Subjects 3 and 4 ranked them first and second. Furthermore, the average recall and precision of lists 1 and 2 were clearly superior to the other four lists. Although the system did not perform as well as Subjects 1 and 2, the system's performance was comparable to those of Subjects 3 and 4.

We performed statistical tests to determine differences among the performances. Based on the $10 \%$ significance level (P: 0.1), the F-test (Analysis of Variance, ANOVA) showed a significance difference in Concept Recall for the 4 subjects, Session, and System output (P: 0.002 in Figure 10). Pairwise two-sample t-tests revealed that Subject 1, Subject

Table 2. continued

\begin{tabular}{|c|c|}
\hline Session: 50 mins. & System: 7 mins. \\
\hline 1. organization & 1. design/product development \\
\hline 2. manufacturability & 2. sale/product engineer/support group \\
\hline 3. program management & 3. team/product engineer/support group \\
\hline 4. market selection & 4. market/product definition/planning/requirement \\
\hline 5. planning & 5. project \\
\hline 6. priorities & 6. customer \\
\hline 7. quality & 7. testing \\
\hline 8. product selection interface & 8. process \\
\hline 9. progress measurement criteria & 9. system \\
\hline 10. design process interface & 10. people \\
\hline 11. development and support tools & 11. management \\
\hline 12. process development & 12. schedule/cycle time/development cycle/control \\
\hline 13. teams & 13. team \\
\hline 14. information systems support & 14. change \\
\hline 15. objectives & 15. goal \\
\hline \multicolumn{2}{|c|}{ 16. resource allocation and development } \\
\hline \multicolumn{2}{|l|}{ 17. military } \\
\hline \multicolumn{2}{|l|}{ 18. financial system } \\
\hline \multicolumn{2}{|l|}{ 19. accountability } \\
\hline 20. training & \\
\hline
\end{tabular}


Table 3. Facilitators' List Evaluation

\begin{tabular}{|c|c|c|c|c|c|c|c|}
\hline \multirow[b]{2}{*}{ Subjects } & & \multicolumn{6}{|c|}{ Lists } \\
\hline & & Subject I & Subject 2 & Subject 3 & Subjece $t$ & Sexion & Sistem \\
\hline Subject 1 & Rank & - & 1 & 2 & 3 & 4 & 5 \\
\hline (46 mins.) & $\begin{array}{l}\text { Target } \\
\text { Identified } \\
\text { Relevant } \\
\text { Recall } \\
\text { Precision }\end{array}$ & $\begin{array}{l}- \\
- \\
- \\
-\end{array}$ & $\begin{array}{r}15 \\
14 \\
13 \\
87 \% \\
93 \%\end{array}$ & $\begin{array}{r}13 \\
7 \\
5 \\
38 \% \\
71 \%\end{array}$ & $\begin{array}{r}12 \\
8 \\
7 \\
58 \% \\
88 \%\end{array}$ & $\begin{array}{r}16 \\
20 \\
13 \\
81 \% \\
65 \%\end{array}$ & $\begin{array}{r}15 \\
13 \\
5 \\
33 \% \\
38 \%\end{array}$ \\
\hline Subject 2 & Rank & 1 & - & 5 & 4 & 2 & 3 \\
\hline (51 mins.) & $\begin{array}{l}\text { Target } \\
\text { Identified } \\
\text { Relevant } \\
\text { Recall } \\
\text { Precision }\end{array}$ & $\begin{array}{r}15 \\
13 \\
10 \\
67 \% \\
77 \%\end{array}$ & $\begin{array}{l}- \\
- \\
- \\
-\end{array}$ & $\begin{array}{r}12 \\
7 \\
2 \\
17 \% \\
29 \%\end{array}$ & $\begin{array}{r}12 \\
8 \\
6 \\
50 \% \\
75 \%\end{array}$ & $\begin{array}{r}14 \\
20 \\
10 \\
71 \% \\
50 \%\end{array}$ & $\begin{array}{r}12 \\
13 \\
7 \\
58 \% \\
54 \%\end{array}$ \\
\hline Subject 3 & Rank & 2 & 1 & - & 5 & 3 & 4 \\
\hline (29 mins.) & $\begin{array}{l}\text { Target } \\
\text { Identified } \\
\text { Relevant } \\
\text { Recall } \\
\text { Precision }\end{array}$ & $\begin{array}{r}15 \\
13 \\
12 \\
80 \% \\
92 \%\end{array}$ & $\begin{array}{r}15 \\
14 \\
14 \\
93 \% \\
100 \%\end{array}$ & $\begin{array}{l}- \\
- \\
- \\
-\end{array}$ & $\begin{array}{r}8 \\
8 \\
0 \\
0 \% \\
0 \%\end{array}$ & $\begin{array}{r}19 \\
20 \\
12 \\
63 \% \\
60 \%\end{array}$ & $\begin{array}{r}12 \\
13 \\
3 \\
25 \% \\
23 \%\end{array}$ \\
\hline Subject 4 & Rank & 1 & 2 & 5 & - & 3 & 4 \\
\hline (55 mins.) & $\begin{array}{l}\text { Target } \\
\text { Identified } \\
\text { Relevant } \\
\text { Recall } \\
\text { Precision }\end{array}$ & $\begin{array}{r}16 \\
13 \\
10 \\
63 \% \\
77 \%\end{array}$ & $\begin{array}{r}16 \\
14 \\
11 \\
69 \% \\
79 \%\end{array}$ & $\begin{array}{r}16 \\
7 \\
1 \\
6 \% \\
14 \%\end{array}$ & $\begin{array}{l}- \\
- \\
-\end{array}$ & $\begin{array}{r}17 \\
20 \\
10 \\
59 \% \\
50 \%\end{array}$ & $\begin{array}{r}16 \\
13 \\
2 \\
13 \% \\
15 \%\end{array}$ \\
\hline $\begin{array}{l}\text { Aver } \\
\text { Averag }\end{array}$ & $\begin{array}{l}\text { ecall } \\
\text { cision }\end{array}$ & $\begin{array}{l}70 \% \\
82 \%\end{array}$ & $\begin{array}{l}83 \% \\
91 \%\end{array}$ & $\begin{array}{l}20 \% \\
38 \%\end{array}$ & $\begin{array}{l}36 \% \\
54 \%\end{array}$ & $\begin{array}{l}69 \% \\
56 \%\end{array}$ & $\begin{array}{l}32 \% \\
33 \%\end{array}$ \\
\hline
\end{tabular}

2, and the session output outperformed our system output in Concept Recall (P: 0.025, 0.013, and 0.027 , respectively). However, our system's Recall level was not statistically different from the Recall levels of the lists generated by Subjects 3 or 4 (P: 0.42 and 0.87 , respectively).

For Concept Precision comparison, the F-test revealed a significant difference among the six lists (P: 0.039), as shown in Figure 11. Twosample t-tests further led us to conclude that Subject 1, Subject 2, and session output did better than our system output at a 0.1 significance level (P: 0.0076, 0.0054, and 0.065, respectively). But our system achieved the same level of Precision performance as Subjects 3 and 4 ( $\mathrm{P}$ : 0.79 and 0.53 , respectively). Figures 10 and 11 also include other important statistics such as: mean (MU), standard deviation (STDEV), degree of freedom (DF), 95 percent confidence interval (CI) for each t-test, and the T-values

\section{Discussion}

Facilitators' comments collected during the evaluation process revealed that subjects had difficulty with the meanings of terms on the system list which contained many single-word terms. These terms did not contain enough meaning or context to determine the concept's relationships with the other terms on the list.

Another major criterion for list evaluation cited by all of the subjects was that each list item needed to be in balance with all of the other terms on the list. That is, each list item should represent a distinct concept separate from any other list item. Additionally, the distinct concept represented by any list item should fit into the same level of abstraction as the other items on the list. While the system list seemed to contain concepts that were conceptually different, it was difficult to attach precise meaning to general topics such as "PEOPLE," "TEAM," and "MANAGEMENT." However, the Hopfield net convergent groups, e.g., "SCHEDULE, CYCLE TIME, DEVELOPMENT TIME, CONTROL" and "MARKET, PRODUC'1 DEVELOPMENT, PLANNING, REQUIREMENT," appeared to be more precise than other single terms and were often selected as relevant by the subjects.

A more detailed evaluation of the lists generated by Subjects 3 and 4 also revealed that these subjects' lists demonstrated problems similar to those observed in our system's output, Subject 3, as shown in Table 2, 
produced only seven general topics. These topics, however, did not represent the meeting topics/ideas at a sufficiently specific level. Subject 4, on the other hand, appeared to be too specific. He summarized what he perceived to be the major problems discussed in the meeting, e.g., "military division requires evaluation." Subjects 1 and 2 were better at capturing the meeting ideas at the right abstraction level.

Even after spending between 50 minutes and 168 minutes in evaluating EBS comments, professional facilitators' performances varied widely. This variation of performance may be due in part to differences in the facilitators' subject area understanding. Despite our effort to choose two sessions which were nontechnical in nature, Subjects 3 and 4 still expressed discomfort with the topics discussed in the manufacturing session. Subjects 1 and 2, however, expressed no difficulty in understanding the meeting topics or in generating their lists for both sessions. Considering the fact that meeting sessions may require facilitators to monitor sessions on topics about which they have little subject area knowledge and in view of the extreme cognitive demand (session facilitation, software and hardware control, group dynamics monitoring, etc.) and time constraints, a wide variation of facilitator performance is expected for real-life meeting processes.

Based on the comments supplied by the subjects, we were able to identify some directions for improving the system's performance and suggestions for using the system's analysis.
- Presenting context: terms on the system list need further expansion in order to provide clearer meaning. One immediate solution would be to allow facilitators or meeting participants to browse the comments associated with the topics on the list and let them make necessary refinements. Because all EBS comments are indexed by the system and can be retrieved and ranked, facilitators or meeting participants could do this. Our bottom-up approach of generating meeting topics from EBS comments provides the added benefit of allow-

Figure 10. Concept Recall comparison: $\mathrm{F}$-test and $\mathrm{t}$-tests

\begin{tabular}{lrrr}
$\begin{array}{lrr}\text { ANALYSIS } \\
\text { SOURCE }\end{array}$ & \multicolumn{4}{l}{ VARIANCE } & MS \\
FACTOR & 5 & 10277 & 2055 \\
ERROR & 14 & 4344 & 310 \\
TOTAL & 19 & 14621 & \\
& & & \\
& & & \\
LEVEL & $\mathrm{N}$ & MEAN & STDEV \\
S1 & 3 & 70.00 & 8.89 \\
S2 & 3 & 83.00 & 12.49 \\
S3 & 3 & 20.33 & 16.26 \\
S4 & 3 & 36.00 & 31.43 \\
SESSION & 4 & 68.50 & 9.71 \\
SYSTEM & 4 & 32.35 & 19.03 \\
& & &
\end{tabular}

POOLED STDEV =

17.62

$\begin{array}{rr}F & P \\ 6.62 & 0.002\end{array}$

INDIVIDUAL 95 PCT CI'S FOR MEAN BASED ON POOLED STDEV

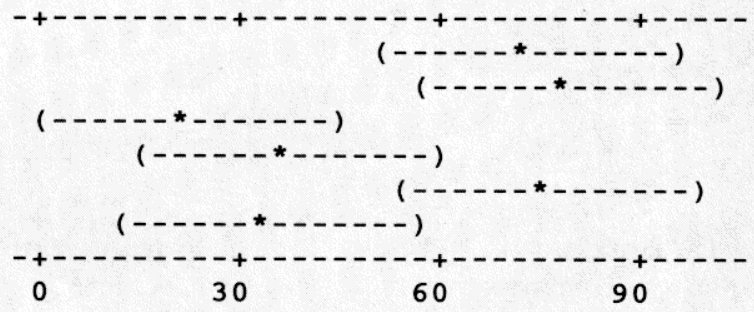

(7.723, 67.78)

$\mathrm{T}=3.49 \quad \mathrm{P}=0.025 \quad \mathrm{DF}=4$

(17.59, 83.91)

$\mathrm{T}=4.25 \quad \mathrm{P}=0.013 \quad \mathrm{DF}=4$

$(-49.04,25.21)$

$\mathrm{T}=-0.89 \quad \mathrm{P}=0.42 \quad \mathrm{DF}=4$

$(-61.46,68.96)$

$\begin{array}{lll}T=0.18 & P=0.87 & D F=\end{array}$

TWOSAMPLE T FOR SESSION VS SYSTEM

95 PCT CI FOR MU SESSION - MU SYSTEM: (6.578, 65.92)

TTEST MU SESSION = MU SYSTEM (VS NE): T= $3.39 \quad \mathrm{P}=0.027 \quad \mathrm{DF}=4$ 
ANALYSIS OF VARIANCE

$\begin{array}{lrrr}\text { SOURCE } & \text { DF } & \text { SS } & \text { MS } \\ \text { FACTOR } & 5 & 8778 & 1756 \\ \text { ERROR } & 14 & 7695 & 550 \\ \text { TOTAL } & 19 & 16473 & \\ & & & \\ & & & \\ \text { LEVEL } & \mathrm{N} & \text { MEAN } & \text { STDEV } \\ \text { S1 } & 3 & 82.00 & 8.66 \\ \text { S2 } & 3 & 90.67 & 10.69 \\ \text { S3 } & 3 & 38.00 & 29.55 \\ \text { S4 } & 3 & 54.33 & 47.50 \\ \text { SESSION } & 4 & 56.25 & 7.50 \\ \text { SYSTEM } & 4 & 32.50 & 17.21\end{array}$

POOLED STDEV $=23.44$

TWOSAMPLE T FOR S1 VS SYSTEM 95 PCT CI FOR MU S1 - MU SYSTEM: TTEST MU S1 = MU SYSTEM (VS NE):

TWOSAMPLE T FOR S2 VS SYSTEM 95 PCT CI FOR MU S2 - MU SYSTEM : TTEST MU S2 = MU SYSTEM (VS NE) :

TWOSAMPLE T FOR S3 VS SYSTEM 95 PCT CI FOR MU S3 - MU SYSTEM: TTEST MU S3 = MU SYSTEM (VS NE):

TWOSAMPLE T FOR S4 VS SYSTEM 95 PCT CI FOR MU S4 - MU SYSTEM: TTEST MU S4 = MU SYSTEM (VS NE) :

TWOSAMPLE T FOR SESSION VS SYSTEM 95 PCT CI FOR MU SESSION - MU SYSTEM: $(-2.324,49.82)$

TTEST MU S4 = MU SYSTEM (VS NE): T=2.53 P=0.065 DF=4

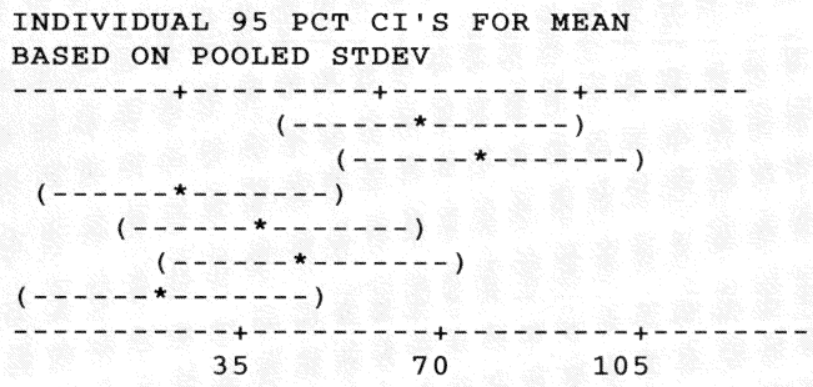

$(21.86,77.14)$

$\mathrm{T}=4.97 \quad \mathrm{P}=0.0076 \quad \mathrm{DF}=4$

$(28.75,87.58)$

$\mathrm{T}=5.49 \quad \mathrm{P}=0.0054 \quad \mathrm{DF}=4$

$(-55.31,66.31)$

$\mathrm{T}=0.29 \quad \mathrm{P}=0.79 \quad \mathrm{DF}=3$

$(-101.8,145.5)$

$\mathrm{T}=0.76 \quad \mathrm{P}=0.53 \quad \mathrm{DF}=3$

Figure 11. Concept Precision comparison: F-test and t-tests

ing humans to trace the justification of the topics suggested.

- Improving specificity: a more computationally intensive solution would involve relaxing the various thresholds we initially set for automatic indexing and cluster analysis. The term-occurrence frequency threshold, previously determined by the information loss analysis, and the cooccurrence frequency cut-off, determined through experimentation, may have caused the system's suggested list to be too general. Some specific terms and unique term relationships may have been cut off prematurely.
In order to improve the system's specificity level, we will need to loosen those thresholds and allow the system to perform more detailed analysis. Currently our system completes the classification process in about 7 minutes for a typical EBS session (our maximum time limit was 15 minutes). We can allow the system to perform more detailed analysis by adopting lower threshold values.

In addition to current batch processing of EBS comments, we are looking into the design of an incremental version of the classification procedure which can process users' EBS comments while they enter them and generate the concept classification incrementally. This incremental version will allow our system to perform more analysis during the realtime EBS meeting session.

\section{Conclusions}

The success of many electronic meeting applications suggests that meeting productivity improves because of the parallelism and anonymity features of the meeting software in supporting divergent tasks. Consolidation and organization of ideas which are convergent tasks are cognitively demanding, however, and pose problems for meeting participants.

The research reported in this article suggests a new approach to assisting the complex process of idea organization. Through the use of information science and artificial intelligence techniques such as automatic indexing, cluster analysis, and Hopfield net classification, we were able to identify the important topics embedded in the EBS comments automatically. Evaluation of our proto- 
type system showed the feasibility of our approach and suggested directions for further improvement.

An active and interactive system component like this can be potentially useful for improving the efficiency and satisfaction of the electronic meeting process. Brainstorming output which is produced by meeting participants in a parallel mode can be analyzed in the background by our system, and a summary of the analysis can be presented to meeting participants for further refinement and articulation. We are in the process of designing an interface for presenting EBS comments associated with the topics that have been classified, relaxing some thresholds, and developing an incremental version of the system. Another major system development effort involves incorporating this concept classification component into the existing GroupSystems software and supporting seamless importation and analysis of EBS comments, graphical display of concept classification, and interactive browsing and refinement by meeting facilitators and participants.
A related long-term system development effort is to investigate the feasibility of using similar techniques to assist in the creation of a conceptbased meeting memory system. We hope to design a "smart" meeting memory system which could analyze, index, and classify any textual electronic meeting information (comments, topics, action plans, voting results, etc.) and allow organization members to retrieve any relevant meeting transcripts, ideas, suggestions, decisions, and so on using uncontrolled vocabularies. The system will be able to identify all conceptually relevant information items for users through the concept space created by the system. This component will in essence exhibit the concept-based information retrieval capability demonstrated in our earlier application [2]. Considering the amount of time managers spend in meetings and the importance of issues discussed and decisions made in these meetings, this concept-based meeting memory management and retrieval capability can become a key to developing a comprehensive and timely computer- based organizational memory. We believe results from our research have shed light on the design of such systems.

\section{Acknowledgments}

We wish to thank Kevin Lynch, Doug Vogel, Mark Fuller, David Paranka, and Daniel Mittleman for participating in this research and contributing constructive criticism. Many thanks for comments on earlier versions of the article are offered to the anonymous referees. C

\section{References}

1. Burton, R.R. Semantic grammar: A technique for efficient language understanding in limited domains. Doctoral dissertation, Computer Science Dept., Univ. of California, Irvine, Ca., 1976.

2. Chen, H., and Lynch, K.J. Automatic construction of networks of concepts characterizing document databases. IEEE Trans. Syst. Man Cybernet. 22, 5 (Sept./Oct. 1992), 885-902.

3. Chen, H., Lynch, K.J., Basu, K., and $\mathrm{Ng}, \mathrm{T}$. Generating, integrating, and activating thesauri for concept-based document retrieval. IEEE EXPERT \& 2 (Apr. 1993), 25-34.

4. Crouch, C.J. An approach to the auto-

\section{Appendix: Topic list produced by our system and the subjects' lists for the educution session}

\begin{tabular}{|l|l|}
\hline Subject 1: 46 mins. & \multicolumn{1}{|l|}{ Subject $2: \mathbf{6 0}$ mins. } \\
\hline 1. business-university dialog/interaction/relationship & 1. dialogue between researchers/practitioners \\
\hline 2. quality/productivity/efficiency & 2. value of business school: research \\
\hline 3. establishing goals/objectives & $\begin{array}{l}\text { 3. value of business school: education/philosophy } \\
\text { of education }\end{array}$ \\
\hline 4. international (language, culture) & 4. difficulty of predicting business needs \\
\hline 5. governance (reward, promotion, leadership) & 5. flexibility of business schools \\
\hline 6. teamwork (group) & 6. row-oriented competence \\
\hline 7. technology (assimilation and management) & 7. current business problems \\
\hline 8. work ethics/values & 8. limited academic resources \\
\hline 9. change management & 9. diversity \\
\hline 10. economics/resource allocation/planning & 10. research vs. application \\
\hline 11. competitive/comparative advantage & \\
\hline 12. organizational learning/organizational memories & \\
\hline 13. environmental issues (management) & \\
\hline
\end{tabular}




\section{Subject 3: 54 mins.}

1. direction of university research

2. teaching methods (case studies)

3. teaching quality (philosophy, principles, culture)

4. studying leadership

5. provide technology-based education in high school

6. limited resources in business schools

7. defining goal of university (knowledge transmission)

8. teaching the ability to think

9. internationalization in teaching

10. internationalization in research

11. teach impacts of time

12. more business education fundamentals down in $\mathrm{K}-12$

13. management of technology

14. long vs. short-term management (increasing long term)

15. changing directions of university research to product orientation

16. changing academic reward systems for relevant research

17. capacity to envision and predict change

18. management of change

19. experimental education increased

20. organizational learning

\section{Session: 55 mins.}

1. technology, change, quality, prod.

2. international

3. demographics, diversity, culture

4. leadership and communication

5. organizational issues

6. discipline, educ., curriculum, research

7. industry, markets, environment

8. environmental issues, social responsibility

9. entrepreneurship, small business

10. competing paradigms

\section{Subject 4: 20 mins.}

1. rows

2. quality

3. problem solving/analytical skills

4. interactive skills

5. interdisciplinary business research

6. greying and browning of America

7. regain business leadership in U.S.

8. creative thinking

9. leadership skills

10. team work

11. language skills/communication skills

12. role of business in social problems

13. management of change

14. work design

15. how to implement these concepts at all levels of education

\section{System: 6 mins.}

1. people

2. teaching

3. skill/management/change/education

4. management education/change

5. curriculum

6. cost accounting

7. time

8. business research

9. learning

10. manager/short-term/training

11. discipline

12. process

13. market

14. environment/economic growth/distribution/subject/lack

15. issues/society/national industrial policy 
matic construction of global thesaur Inf. Process. Manage. 26, 5 (1990), 629 640.

5. Dalton, J. and Deshmane, A. Artificial neural networks. IEEE Pot. 10, 2 (Apr 1991), 33-36.

6. Ellis, C.A., Gibbs, S.J., and Rein, G.1. Groupware: Some issues and experi ences. Commun. ACM 34, 1 (Jan. 1991), 38-58.

7. Everitt, B. Cluster Analysis. 2d ed Heinemann Educational Books, London, England, 1980

8. Fillmore, C.J. The case for case. In Universals in Linguistic Theory. Holt, Rinehart, and Winston, New York, 1968.

9. George, J.F., Easton, G.K. Nunamaker, J.F., and Northcrafi, G.B. A study of collaborative group work with and without computer based support. Inf. Syst. Res. 1, 4 (Dec 1990), 394-415.

10. Hopfield, J.J. Neural network and physical systems with collective computational abilities. Proc. Nat. Acad. Sci. 78, 8 (1982).

11. Huber, G.P. Effects of decision and communication technologies on organizational decision processes and structures. In Organizational Decision Support Systems. North Holland, Amsterdam, 1988, pp. 317-333.

12. Johansen, R. Groupware: Computer Support for Business Teams. The Free Press, New York, 1988.

13. Kirkpatrick, D. Here comes the payoff from PCs. Fortune (Mar. 23, 1992), 93-100.

14. Knight, K. Connectionist ideas and algorithms. Commun. ACM 33, 11 (Nov. 1990), 59-74.

15. Lippmann, R.P. An introduction to computing with neural networks. IEEE Acoust. Speech Sig. Process. Mag. 4, 2 (Apr. 1987), 4-22.

16. Michalski, R.S., and Stepp, R.E. Learning from observation: Conceptual clustering. In Machine Learning, An Artificial Intelligence Approach. Tioga Publishing Company, Palo Alto, Ca., 1983, pp. 321-363.

17. Newell, A. and Simon, H.A. Human Problem Solving. Prentice-Hall, Englewood Cliffs, N.J., 1972.

18. Nunamaker, J.F., Dennis, A.R. Valacich, J.S., Vogel, D.R., and George, J.F. Electronic meeting systems to support group work. Commun. ACM 34, 7 (July 1991), 40-61.

19. Salton, G. Automatic Text Processing. Addison-Wesley, Reading, Mass., 1989.

20. Salton, Generation and search of clustered files. ACM Trans. Database Syst. 3 , 4 (Dec. 1978), 321-346.
21. Sparck Jones, K. Notes and references on early automatic classification work ACM SIGIR Forum 25, 1 (Spring 1991), 10-17

22. Sparck Jones, K. Automatic Keyword Classification for Information Retrieval. Butterworths, London, 1971.

23. Tank, D.W. and Hopfield, J.J. Collec tive computation in neuronlike circuits. Sci. Am. 257,6 (Dec. 1987), 104114.

24. Walsh, J.P. and Lngson, G.R. Organi zational memory. Acad. Manage. Rev 16, 1 (1991), 57-91.

25. Woods, W.A. An experimental parsing system for transition network grammars. In Natural Language Processing. Algorithmics Press, New York, 1972

\section{About the Authors:}

H. CHEN is assistant protessor in the Management Information Systems Department, University of Arizona. His research interests include digital library systems, internet resource discovery, intelligent information retrieval, and computer-supported cooperative work.

P. HSU is senior engineer in the Advanced Packaging Development Department at the LSI Logic Corporation, Fremont, Calif. His research interests include signal integrity and electronic packaging. Author's Current Address: LSI Logic Corporation, 48580 Kato Rd., MS K-300, Fremont, CA 94539, pch@lisl.com.

R. ORWIG is a Ph.D. candidate in the Management Information Systems Department, University of Arizona. His research interests include neural network computing, business process re-engineering, and computer-supported cooperative work.

L. HOOPES is system manager in the Management Information Systems Department, University of Arizona. His research interests include user interface design and text processing.

J.F. NUNAMAKER heads the Center for the Management of Information at the University of Arizona where he is a Regents professor. His research interests include group decision support systems, electronic meeting systems, and computer-aided support of systems analysis and design.

Authors' Present Address (for Chen, Orwig, Hoopes, Nunamaker): Dept. of Management Information Systems, University of Arizona, Tucson, AZ 85721, hchen@uabpa.arizona.edu, rorwig@ uabpadrizona.edu, hoopes(a uabpa arizona. edu, nunamaker $(a$ uabpa.arizona edu.

This project was supported in part by an NSF CISE Research Initiation Award (NSF IRI 9211418, 1992-1994) and U.S. Army Corp of Engineers and U.S. Army Research Lab Awards $(1992-1994)$.

Permission to copy without fee all or part of this material is granted provided that the copies are not made or distributed for direct commercial advantage, the AC:M copvright notice and the title of the publication and its date appear, and notice is given that copying is by permission of the Association for Computing Machinery. To copy otherwise, or to republish, requires a fee and/or specific permission.

C AC.M 0002-0782/94/01000 \$3.50 